\section{The role of leadership in developing and sustaining teachers' professional learning}

\author{
Fiona King
}

Management in Education 000(00) I-7

(C) 20II British Educational Leadership, Management \& Administration Society (BELMAS)

Reprints and permission:

sagepub.co.uk/journalsPermissions.nav DOI: | 0. I |77/08920206 | |40979 |

mie.sagepub.com

\begin{abstract}
A prominent feature of education discourse relating to teachers' practice has been the call for increased emphasis on professional development (PD). This paper is part of a wider project which explored the impact of a collaborative PD initiative on teachers' teaching and learning in five urban disadvantaged schools in Ireland. It focused on the impact of PD and critically on sustainability from which emerged important issues of leadership. This article focuses on the specific contribution that leadership made to the sustainability of the practices in the schools. It aims to identify three key features of how principals contribute to sustaining PD practices.
\end{abstract}

\title{
Keywords
}

professional development, sustainability, leadership, creating organisational capacity, professional learning communities

\section{Introduction}

A large volume of educational research exists relating to changes in the diversity of our classrooms and the importance of teacher expertise in facilitating these changes. Central to this is teacher PD which aims to improve pupil outcomes (Earley \& Porritt, 2010) and support school improvement (Syed, 2008), although establishing this relationship is notoriously difficult (Kratochwill et al., 2007). A particular feature of this research is that there is often a considerable focus on short-term actions with long-term impact ignored (Ofsted, 2006: 21; Timperley, 2008). A crucial dimension for long-term school improvement is sustaining change and yet very little research exists on whether schools sustain the use of new practices (Baker et al., 2004). Schools need help sustaining practices and while teacher PD has been the focus of the 'new professionalism' agenda (Guskey, 1996; Slater, 2004; Stevenson, 2010 ) it has resulted in some teachers viewing PD as conforming to departmental or governmental regulations (Neil \& Morgan, 2003) under an umbrella of accountability and performativity (Purdon, 2004; Ball, 2003) in a new managerialist system (Evans, 2008; Crawford, 2009). Adding to this is the highly individualistic nature of teaching (Burbank \& Kauchak, 2003) resulting in limited access to new ideas (Hargreaves \& Fullan 1992) and little reflective practice. Hargreaves (1994) has advocated a 'new professionalism' which promotes teacher collaboration and teacher involvement in decision-making, problem-solving and planning PD (Webb, 2007) which in turn fosters teacher autonomy and ownership in relation to school improvement (Seed, 2008). Whether this form of distributed leadership (Dinham et al., 2008) is part of the new managerialism or represents a more meaningful empowerment of teachers may depend crucially on the actions of school leaders and how leadership is exercised in schools.
This paper draws on work which explores issues of PD and sustainability and which seeks to identify and understand institutional factors that appear to either support or impede the longer-term sustaining of new practices. Within the initial findings the issue of school leadership, and how it is practised, has emerged as a key issue in determining whether or not new professional practices resulting from teacher PD are sustained and embedded. This paper presents this data and seeks to identify the specific role of school leaders in supporting the longer-term impact of teacher PD.

This work focuses on a specific initiative undertaken with a group of schools in the Republic of Ireland. The PD involved teachers from five urban disadvantaged schools as categorised by the Social Inclusion Section of the Department of Education and Skills (DES) using the DEIS (Delivering Equality of Opportunity in Schools) Banding categorisation. The five schools were selected from 19 schools that applied to an advertisement in the Irish National Teachers Organisation (INTO) (teacher union) magazine inviting schools to participate in a literacy initiative in which they would be supported and funded by the INTO. Funding provided all materials, the input of a project facilitator and time off for teachers to attend training. Further support was provided in terms of two school visits during the ten-week period and access to support via e-mail and telephone. The initiative focused on pupils in 3rd class (average age 9) and required a special educational needs (SEN) teacher and a classroom teacher to work collaboratively within the mainstream classroom to facilitate Peer Tutoring (PT) (Topping, 1988) for literacy for 30 minutes a day, four days a week, over a ten-week period. PT

Corresponding author:

E-mail: fionac.king@gmail.com 
involves pupils reading in mixed ability pairs in the role of tutor and tutee with the aim of improving their reading accuracy and fluency. Findings from the initiative in 2008 appeared to show an overall average improvement of 12.7 months in reading accuracy for pupils $(n=116)$, high levels of pupils' enjoyment and teachers' willingness to sustain the practices beyond the initial input. This paper is a report of a 'work in progress' in terms of findings as to whether these practices have been sustained in the same five schools and the crucial role of leadership in this process.

\section{Teachers' professional learning}

In order to relate to teachers' professional learning it is important firstly to understand the term professional. One approach to identifying a claim to being a professional is to identify occupational groups that have a claim to specialist knowledge and have the capacity and trustworthiness to use it to provide a continually improving service for society (Forde et al., 2009: 12; O'Sullivan \& West-Burnham, 2011). However, this concept of professionalism is increasingly being contested with Kennedy (2007) identifying two distinct models: democratic professionalism and managerial professionalism. The latter model values effectiveness, efficiency and compliance with policy while the democratic perspective values social justice, fairness and equality (Kennedy, 2007: 99). While the democratic model of professionalism is espoused in literature the managerial model which is linked to globalisation is arguably more dominant in reality (Smyth et al., 2000). This is reflected in the emergence of a 'new professionalism' often defined in terms of accountability, external targets and performance management (Bell \& Bolam, 2010). One consequence is that individual teacher and school development needs are both subjugated to the needs of national strategy with the potential to promote system uniformity and suffocate innovation and risk-taking (Webb, 2007). The challenge for teachers is to find the 'spaces' within this dominant agenda and to be professional in the sense that they embrace national strategies in a critical rather than prescriptive way as there is no one size that fits all (Bell \& Bolam, 2010). In so doing they are better able to further their own professional learning in a way that is consonant with their professional values (Booth, 2003) and context. In addition to 'space' teachers need PD, i.e. 'processes, activities and experiences that provide opportunities to extend teacher professional learning' (NSW Institute of Teachers, 2007: 3 ). Ironically governments have spent vast amounts of money on delivering PD and yet little evidence exists on the impact it has had on improved pupil outcomes. This relationship is not automatic (Cumming, 2002) with teachers needing support to build their capacity to result in improved pupil outcomes.

\section{The role of leadership in the development and sustainability of PD}

'Professional development does not just happen - it has to be managed and led' (Earley \& Bubb, 2004: 80) or led and supported (NCCA, 2010). Therefore leadership may vary from what is termed transactional or transformational with the former operating on the premise of motivating teachers to change through extrinsic rewards and the latter focused on changing attitudes resulting in changes in practice and development of shared values (Ingram, 1997) or changing practices resulting in changing attitudes (Guskey, 2002). This is somewhat reflective of managerial and democratic professionalism in the way that they manage and lead PD in comparison to leading and supporting through transformational leadership.

Within the debates about effective PD it is possible to argue that a consensus has emerged relating to a number of central features of such provision. There is, for example, a recognition that effective $\mathrm{PD}$ should be activity focused with opportunities for application in practice, be evidence-based and allow for critical reflection (Bell \& Bolam, 2010; O'Sullivan \& West-Burnham, 2011) where teachers have opportunities to learn and reflect together through collaborative PD (Ainscow et al., 2000). Collaborative PD is 'where there are specific plans to encourage and enable shared learning and support between at least two teacher colleagues on a sustained basis' (Cordingley et al., 2004: 2). Through the development of collaborative practices it is argued that teachers can be empowered to change their practices to enhance pupils' learning (Friend \& Cook, 2000). Leadership plays a pivotal role in fostering collaboration between teachers through building collegiality based on trust and respect (Lugg \& Boyd, 1993) where all parties have equal status and input is highly regarded (Slater, 2004). In the absence of these features, and where principals advocate changes in a managerialist and top-down approach, a form of 'contrived collegiality' (Hargreaves, 1994) may result with a negative impact on the longerterm sustaining of collaborative practices (Fallon \& Barnett, 2009).

However, leadership can help sustain changes through the ongoing development of cultures of learning (Leonard, 2002; Fullan et al., 2005) where teachers have the opportunity to work with a facilitator on their practice (Guskey, 1991; Bolt, 2007) and get involved in the development of a professional learning community (PLC) (Kervin, 2007). PLCs emphasise the importance of collaborative work that focuses on shared aims in teaching and learning and reflective professional inquiry (Bolam et al., 2005), resulting in teachers having more autonomy and ownership in relation to school improvement (Seed, 2008) through a form of distributed leadership (Dinham et al., 2008). PLCs are instrumental in sustaining change and the literature is replete with endorsements of their potential for influence (Eaker et al., 2002; Bolam et al., 2005). Despite this they are not prevalent in many schools (Harris, 2001). It is accepted that creating and sustaining such cultures is at best arduous (Nevin et al., 1993) and at worst dubious (Leonard, 2002), perhaps because they may be predicated on 'contrived collegiality' in an attempt to conform and meet the criteria of accountability as laid out, for example, in Whole School Evaluation or Ofsted inspections. However, they can be developed through support from leadership for 
teachers to work collaboratively on an initiative which if successful may act as an impetus for change (Goos et al., 2007) and lead to the development of other collaborative practices. In this way collaboration and PLCs are an outcome of collaborative PD and not something that is enforced.

'Organisational capacity which consists of providing training and ongoing support for teachers is an essential element in the change process' (Fullan, 2005) and one which is also led by the principal. Teachers working in supportive environments can reach higher stages of development (Phillips \& Glickman, 1991). Effective leadership is defined as: talking with teachers and promoting teachers' professional growth and reflection (Blasé and Blasé, 1998: 3 ) through providing time and resources (Neil \& Morgan, 2003; Rhodes et al., 2004). A review on the impact of PD reported findings from 11 out of 17 studies highlighting the need to provide agreed non-contact time to facilitate collaborative lesson planning for sustained teacher development (Cordingley et al., 2003) and time for critical reflection and consolidation of learning (Neil \& Morgan, 2003; Smith, 2007) which makes teachers feel that what they are doing is valued (Stevenson, 2008). This need for principals to provide time for collaboration is also reflected in the results from a longitudinal study which posits that sustaining change over time requires sustaining deep learning and knowledge (Bolam et al., 2005) and consolidating that learning in day-to-day practices (Earley \& Porritt, 2010) where teachers' understanding moves from a procedural level to a conceptual level and their use of new and improved knowledge and skills is at a refined level where practices are continually improving to better meet the needs of learners (Hall \& Hord, 2001; Baker et al., 2004). Sustaining change also requires having plans for disseminating findings or sharing effective practices (Goos et al., 2007) which also requires support from leadership. Without such cascading, practices will not be sustained in schools where the teachers involved in the initial initiative may have moved on or there has been a change in leadership (Hargreaves \& Fink, 2003).

Cordingley et al. (2004: 61) have advocated that all these elements of sustaining change need to be considered in designing and evaluating PD given the link between sustainability of practices and effective PD and school improvement as espoused by the Elementary and Secondary Education Act 2001 and Desimone (2009). Principals have a role in this process where they give teachers autonomy to balance meeting their own professional needs, their institutional needs and those of the state (Bell \& Bolam, 2010). Desimone (2009) argues the most influential feature of effective PD is content with teachers looking for practices that are feasible (Darling-Hammond, 1997; Goos et al., 2007), suitable for all their pupils and have readily available materials (Boardman et al., 2005). Intrinsic to the processes of change and sustaining change are resources for teachers to 'think, reflect, negotiate their way, plan, try out, review, and share ideas and experiences' (NCCA, 2010: 13). Principals have an important role to play in meeting teachers' needs in this regard as teachers who are experiencing a lack of time for collaboration, funding issues or a mismatch between the practice and state mandates may not sustain such practices.

\section{Methods}

A multiple case study approach was used to carry out this qualitative research to get an overview of teachers' involvement in the collaborative PD initiative. The sampling used was the same five schools from the original project and the three people (principal, classroom teacher, SEN teacher) within those schools that were originally involved in the collaborative initiative. However, some of the original staff had moved on and, given the flexible nature of case study research, this allowed for interviews to be carried out with people in those schools who have since become involved in the practice.

\section{Findings and Discussion}

Emergent findings from this wider study on developing and sustaining teachers' professional learning highlight three themes around the centrality of leadership in sustaining educational change in schools.

\section{Theme one: alignment between teachers' and principals' values}

Teachers were largely responsible for bringing an awareness of the literacy initiative to the principals. Teachers' motivation for getting involved centred on improving literacy which aligned well with principals' values in that being a disadvantaged school results in literacy being of significant importance. While teachers may have been the driving force for getting involved in this initiative, their perceptions and that of principals being aligned resulted in principals opting their schools into the initiative and thus provided strong supportive preconditions for capacity building for change (Bjorkman \& Olofsson, 2009). Furthermore, two of the principals were thinking long-term and saw this as a 'vehicle' for introducing collaborative practices between class teachers and SEN teachers in the school. Interestingly none of the teachers involved cited the collaborative aspect of the initiative as being a reason for opting into it.

\section{Theme two: creating organisational capacity for change}

Principals were instrumental in securing a class teacher and an SEN teacher willing to work collaboratively on the literacy practice. It was not mandated in any of the schools with principals positing that if you 'mandate it you always get resistance'. They felt if teachers elected to get involved and it was successful, it might lead to its sustainability, changes in attitude and thus real change, an approach akin to Ingram's (1997) transformational leadership.

Four out of the five principals personally attended the in-service day for the collaborative initiative which provided procedural and conceptual knowledge and research 
findings about PT. Supporting teachers in this way showed that they valued the initiative (Stevenson, 2008) which is something teachers highlighted as being important. The fifth principal asked the literacy coordinator to attend as she was prepared to support teachers willing to undertake it. Interestingly, the practice has not been sustained in this school despite the class teacher wanting to continue it. $\mathrm{He}$ tried it the following year but without an SEN teacher being timetabled to work with him it was not possible to sustain it.

Interestingly, another school which has had a change of leadership has sustained the practice. The new principal was directly involved in learning about the initiative and showed conceptual as well as procedural knowledge which is required for sustaining practices (Baker et al., 2004). This raises the issue of principals being involved and facilitating awareness of practices at conceptual levels for sustainment, a finding reflected by the class teacher who wanted to sustain it: 'Because of the fact of the training, there's not much understanding for it.' Teachers need opportunities to share and reflect together for sustainment.

Following year one a number of leadership practices around creating organisational capacity for change appeared to contribute to its sustainability within schools in subsequent years. All teachers stated that the initiative required the principal to support it thus providing topdown support for a bottom-up approach (DarlingHammond \& McLaughlin, 1995). Principals were happy to manifest their support as they valued the initiative largely due to having evidence in terms of pupils' outcomes and they saw that it was leading to more collaborative practices within their schools. This support came in the format of providing time for teachers to collaborate for planning (Cordingley et al., 2003), to critically reflect on practices and to consolidate their learning (Neil \& Morgan, 2003; Smith, 2007). Principals cited difficulties in doing this at times due to other pressures but made it a priority to help teachers move from procedural to conceptual levels of understanding with some facilitating cover for classes to allow for this time. This non-contact time was given during school time, one school subsequently moving this to outside of school hours with the principal stating that teachers now value it themselves and want to continue it. Support was also provided in terms of resources, i.e. any books or folders needed. Timetabling was cited by teachers as one area where they needed the support of principals to ensure sustainability. The initiative lasts for 10 weeks per year and teachers need to be timetabled to work together during this time. This requires planning in advance and principals supporting this process. Teachers also felt that sustaining practices requires an advocate or someone assigned to oversee the process each year and someone to put it on the agenda at staff meetings. In each of the four schools where the initiative was sustained a teacher has voluntarily taken this role upon themselves. As teachers elected to get involved in the first place they subsequently took ownership of the process and brought it to the principal each year for approval and support.

What is significant about principals creating organisational capacity for change is that they did so and did not micromanage the initiative in which they had hugely invested in terms of time, timetabling and resources. While principals realised that it would not have developed and survived without this much needed support it required a leap of faith in the teachers. This investment in trusting teachers as professionals was cited as a major contributing factor in its development and sustainment by teachers in one school who described their principal as being "very trusting of the learning support team'. Trust is central to risk taking and innovative practices both of which are crucial for school development and improvement. Principals trusted teachers and gave them the autonomy to embark on this initiative, supported them through developing organisational capacity and gave them the space to implement it in their classrooms. One principal argued that 'people have strengths and there are people who are better at areas of curriculum than I am and use that, let them off and they do it very well.' This enabling style of leadership which gives teachers a lot of scope to develop things for themselves can be difficult with the 'new culture of competitive performativity' which means principals have the onerous task of imparting the culture of accountability while preserving teacher morale, commitment and identity (Ball, 2003: 219).

\section{Theme three: empowering teachers to create collaborative learning cultures and PLCS}

Teachers' desire to sustain the practices rested with the positive impact they were having on their pupils. However, one challenge was the high rates of staff turnover thus requiring practices to be extended to other teachers in the school. 'There needs to be a culture sharing, but there also needs to be a mechanism to share', reported one class teacher. This requires support from principals to facilitate the development of cultures of learning (Leonard, 2002; Fullan et al., 2005) with teachers being encouraged to become leaders themselves through modelling practices for others (Goos et al., 2007) and having time to collaboratively plan and evaluate. This distributed leadership which was encouraged by principals resulted in teachers taking ownership of the practices and developing PLCs focusing on coordinating such practices with the shared aim of improving pupils' outcomes (Bolam et al., 2005). Interestingly principals realised they had 'to be mindful of personalities with collaborative practice' and always ensure that teachers knew they were under no pressure to participate. However, through the development of PLCs and teachers' enthusiasm for the initiative other teachers were willing to try it. Also, when principals were hiring staff they looked for teachers who were willing to work collaboratively. So over the last three years cascading of practices within four of the schools has been significant with one school now having all their teachers participating in the initiative. It is also worth noting that through the development of PLCs teachers did not just employ a technical approach to this initiative, rather they challenged it and adapted it accordingly to meet the needs of their particular classes thus showing evidence of deep learning which is a prerequisite of sustaining practices 
and school improvement. They showed an awareness that no one size fits all and that they sustain practices that work (Boardman et al., 2005) with the support of leadership.

All principals reported a significant positive impact in terms of collective outcomes. None of the teachers in these four schools had previously worked collaboratively within the same classroom and now 'the whole issue of teachers coming into classes has also spread. We have all support (SEN) teachers going in for maths.' 'It is now accepted practice.' 'It's part of what we do now in literacy.' Teachers reported feeling 'more comfortable with collaborative approaches' and having learned a lot from each other as teachers. This mentoring aspect was an unexpected outcome for teachers but one that they felt was hugely beneficial. Despite not continuing the practice the principal of the fifth school stated 'it was very good, it planted a seed' and we have 'shifted enormously in our thinking'. They now have many collaborative practices in the school but have not sustained the use of the PT.

Through their enabling and transformational style of leadership principals encouraged teachers to develop PLCs to sustain practices. Teachers were delighted to sustain the practices with the necessary support from principals. Principals were happy to support the practices as teachers valued them and they were impacting on school development and improvement which brings us back to theme number one: alignment between teachers' and principals' values.

\section{Conclusion}

It is accepted that the concepts of teacher PD, collaborative practices and PLCs are complex yet essential components linking teaching and school improvement. However, they are often treated as separate entities in the literature with little research available on the convergence of these concepts in practice. These components did, however, come together where teachers voluntarily undertook collaborative PD with the aim of improving pupils' literacy outcomes. Leadership played a pivotal role in creating the conditions and culture necessary for developing and sustaining teachers' professional learning through enabling collaborative PD, i.e. shared learning and support among teachers on a sustained basis leading to enhanced teacher expertise and skills (Cordingley et al., 2004). This enabling form of leadership was responsible for teachers having the confidence to bring the initiative to the principal initially which subsequently led to distributed leadership giving teachers the autonomy to embark on collaborative PD to meet their professional and individual needs. Leadership also supported teachers in developing PLCs to sustain their practices. The implications for leadership from this research are to develop an enabling or transformational style which empowers teachers through distributed leadership, based on trust, to participate in PD, collaboration and PLCs as a means for school improvement. It highlights the centrality of teachers in the change process towards school improvement and the significant role of principals in leading and supporting that change.

\section{References}

Ainscow, M., Beresford, J., Harris, A., Hopkins, D., Southworth, G. \& West, M. (2000) Creating the Conditions for School Improvement, 2nd edn. London: David Fulton.

Baker, S., Gerston, R., Dimino, J. A. \& Griffiths, R. (2004) 'The sustained use of research-based instructional practice: a case study of peer-assisted learning strategies in mathematics'. Remedial and Special Education, 25(1), 5.

Ball, S. (2003) 'The teacher's soul and the terrors of performativity'. Journal of Education Policy, 18(2), 215-28.

Bell, L. \& Bolam, R. (2010) 'Teacher professionalism and continuing professional development: contested concepts and their implications for school leaders'. In T. Bush, L. Bell \& D. Middlewood (eds), The Principles of Educational Leadership and Management, pp. 89-111. London: Sage.

Bjorkman, C. \& Olofsson, A. (2009) 'Qualitative descriptions of pre-conditions for capacity-building in schools'. International Studies in Educational Administration, 37(2), 25-40.

Blasé, J. \& Blasé, J. (1998) 'Supporting the lifelong study of learning and teaching'. International Electronic Journal for Leadership in Learning, 2(7).

Boardman, A. G., Arguelles, M. E., Vaughn, S., Hughes, M. T. \& Klinger, J. (2005) 'Special education teachers' views of research-based practices'. Journal of Special Education, 39(3), 168ff.

Bolam, R., McMahon, A., Stoll, L., Thomas, S., Wallace, M., Greenwood, A., Hawkey, K., Ingram, M., Atkinson, A. \& Smith, M. (2005) Creating and Sustaining Effective Professional Learning Communities, Report No. RB637. Nottingham: DfES Publications.

Bolt, S. (2007) 'The challenge of integrating research, action and learning in the workplace to affect organisational change'. International Journal of Pedagogies and Learning, 3(2), 42-51.

Booth, S. (2003) 'Inclusion and exclusion in the city: concepts and contexts'. In P. Potts (ed.), Inclusion in the City: Selection, Schooling and Community. London: RoutledgeFalmer.

Burbank, M. D. \& Kauchak, D. (2003) 'An alternative model for professional development: investigations into effective collaboration'. Teaching and Teacher Education, 19, 499-514.

Cordingley, P., Bell, M. \& Thomason, S. (2004) Continuing Professional Development (CPD) Review Group. The impact of collaborative CPD on classroom teaching and learning. Protocol: How do collaborative and sustained CPD and sustained but not collaborative CPD affect teaching and learning? Online at: http://eppi.ioe.ac.uk/EPPIWebContent/reel/ review_groups/CPD/cpd_protocol2.pdf (accessed December 2009).

Cordingley, P., Bell, M. \& Thomason, S. (2008) Continuing Professional Development (CPD): The Evidence Base. Prepared by the Centre for the Use of Research and Evidence in Education (CUREE). Online at: http://www.tda.gov.uk/upload/ resources/pdf/e/eppi_research.pdf (accessed December 2009).

Cordingley, P., Bell, M., Rundell, B. \& Evans, D. (2003) 'The impact of collaborative CPD on classroom teaching and learning'. In Research Evidence in Education Library. London: EPPI-Centre, Social Science Research Unit, Institute of Education, University of London. 
Crawford, K. (2009) 'Continuing Professional Development in Higher Education: Voices from Below'. Unpublished EdD, University of Lincoln, Lincoln.

Cumming, J. (2002) 'Working together as a profession'. Unicorn, 28(2), 1-4.

Darling-Hammond, L. (1997) The Right to Learn: A Blueprint for Creating Schools that Work. San Francisco: Jossey-Bass.

Darling-Hammond, L. \& McLaughlin, M. W. (1995) 'Policies that support professional development in an era of reform'. Phi Delta Kappan, 76(8), 597-604.

Department of Education and Skills (Ireland) (n.d.) Social Inclusion - Programmes and Schemes - Delivering Equality of Opportunity in Schools (DEIS). Online at: http://www.education.ie/ home/home.jsp?maincat $=17216 \&$ pcategory $=17216 \&$ ecategory $=33128 \&$ language $=\mathrm{EN}$.

Desimone, L. M. (2009) 'Improving impact studies of teachers' professional development: toward better conceptualizations and measures'. Educational Researcher, 38(3), 181-99.

Dinham, S., Aubusson, P. \& Brady, L. (2008) 'Distributed leadership as a factor in and outcome of teachers action learning'. International Electronic Journal for Leadership in Learning, 12(4). Online at: http://www.ucalgary.ca/iejll/vol12 (accessed September 2010).

Eaker, R., DuFour, R. \& DuFour, R. (2002) Getting Started: Reculturing Schools to Become Professional Learning Communities. Bloomington: IN: Solution Tree (formerly National Educational Service).

Earley, P. \& Bubb, S. (2004) Leading and Managing Continual Professional Development. London: Sage.

Earley, P. \& Porritt, V. (2010) Effective Practices in Continuing Professional Development. London: Institute of Education, University of London.

Evans, L. (2008) 'Professionalism, professionality and the development of education professionals'. British Journal of Educational Studies, 56(1), 20-38.

Fallon, G. \& Barnett, J. (2009) 'When is a learning community just a pseudo community? Towards the development of a notion of an authentic learning community'. International Studies in Educational Administration, 37(2), 3-24.

Forde, C., McMahon, M. \& Reeves, J. (2009) Putting Together Professional Portfolios. London: Sage.

Friend, M. \& Cook, L. (2000) Interactions: Collaboration Skills for School Professionals, 3rd edn. White Plains, NY: Longman.

Fullan, M., Cuttress, C. \& Kilcher, A. (2005) ' 8 forces for leaders of change'. Journal of Staff Development, 26(5), 54-64.

Goos, M., Dole, S. \& Makar, K. (2007) 'Designing professional development to support teachers' learning in complex environments'. Mathematics Teacher Education and Development, 8 (Special Issue), 23-47.

Guskey, T. R. (1991) 'Enhancing the effectiveness of professional development programs'. Journal of Educational and Psychological Consultation, 2(3), 239-47.

Guskey, T. R. (1996) 'Jointly planning staff training'. School Administrator, 53(11), 33.

Guskey, T. R. (2002) 'Does it make a difference? Evaluating professional development'. Educational Leadership, 59(6), 45-51.

Hall, G. E. \& Hord, S. M. (2001) Implementing Change: Patterns, Principles, and Potholes. Boston: Allyn \& Bacon.
Hargreaves, A. (1994) Changing Teachers, Changing Times: Teachers' Work and Culture in the Postmodern Age. New York: Teachers College Press.

Hargreaves, A. \& Fink, D. (2003) 'Sustaining leadership'. Phi Del Kappan, 84(9), 693-700.

Hargreaves, A. \& Fullan, M. (eds) (1992) Teacher Development and Educational Change. Basingstoke: Falmer.

Harris, A. (2001) 'Building the capacity for school improvement'. School Leadership and Management, 21(3), 261-70.

Kennedy, A. (2007) 'Continuing professional development (CPD) policy and the discourse of teacher professionalism in Scotland'. Research Papers in Education, 22(1), 95-111.

Kervin, L. (2007) 'Supporting elementary teachers at the "chalkface": a model for in-school professional development. International Electronic Journal for Leadership in Learning, 11(10). Online at: http://www.ucalgary.ca/iejl1/vol11/kervin (accessed December 2008).

Klinger, J. K., Ahwee, S., Piloneita, P. \& Menendez, R. (2003) 'Barriers and facilitators in scaling up research-based practices'. Exceptional Children, 69(4), $411 \mathrm{ff}$.

Kratochwill, T., Volpiansky, P., Clements, M. \& Ball, C. (2007) 'Professional development in implementing and sustaining multitier prevention models: implications for response to intervention'. School Psychology Review, 36(4), 618.

Leonard, L. J. (2002) 'Schools as professional communities: addressing the collaborative challenge'. International Electronic Journal for Leadership in Learning, 6(17). Online at: http:// www.ucalgary.ca/iej11/vol10/leonard (accessed June 2010).

Lugg, C. A. \& Boyd, W. L. (1993) 'Leadership for collaboration: reducing risk and fostering resilience'. Phi Del Kappan, 75(3), $253 \mathrm{ff}$.

National Council for Curriculum and Assessment (NCCA) (2010) Leading and Supporting Change in Schools, Discussion Paper. Online at: http://www.ncca.ie/en/Old\%20Publications\%20listing/ Leading_and_Supporting_Change_in_Schools.pdf. (accessed January 2011).

Neil, P. \& Morgan, C. (2003) Continuing Professional Development for Teachers: From Induction to Senior Management. London: Kogan Page.

Nevin, A., Thousand, J. S. \& Villa, R. A. (1993) 'Establishing collaborative ethics and practices'. Journal of Educational and Psychological Consultation, 4(4), 292-304.

NSW Institute of Teachers (n.d.) Continuing Professional Development Policy. Online at: http://www.nswteachers.nsw.edu.au/IgnitionSuite/uploads/docs/Continuing\%20Professional\%20Development\%20Development\%20Policy.pdf (accessed November 2008).

O'Sullivan, H. \& West-Burnham, J. (2011) Leading and Managing Schools.

Ofsted (2006) The Logical Chain. London: Ofsted.

Phillips, M. D. \& Glickman, C. D. (1991) 'Peer coaching: developmental approach to enhance teacher thinking'. Journal of Staff Development, 12(2), 20-5.

Purdon, A. (2004) 'Perceptions of the educational elite on the purpose of a national framework of continuing professional development (CPD) for teachers in Scotland [1]'. Journal of Education for Teaching, 30(2), 131-49.

Rhodes, C., Stokes, M. \& Hampton, G. (2004) A Practical Guide to Mentoring, Coaching, and Peer-Networking: Teacher 
Professional Development in Schools and Colleges. New York: RoutledgeFalmer.

Seed, A. H. (2008) Redirecting the teaching profession in the wake of a nation at risk and NCLB'. Phi Delta Kappan, 89(8), 586.

Slater, L. (2004) 'Collaboration: a framework for school improvement'. International Electronic Journal for Leadership in Learning, 8(5). Online at: http://www.ucalgary.ca/iejll/vol8/ Slater (accessed December 2008).

Smith, R. G. (2007) 'Developing professional identities and knowledge: becoming primary teachers'. Teachers \& Teaching, 13(4), 377-97.

Smyth, J., Dow, A., Hattam, R., Reid, A. \& Shacklock, G. (2000) Teachers' Work in a Globalizing Economy. London: Falmer Press.

Stevenson, H. (2008) 'Teacher development through practitioner research and cross-school collaboration: possibilities and limitations'. In Ling-po Shiu and John Chi-Kin Lee (eds), Developing Teachers and Developing Schools in Changing Contexts. Hong Kong: Chinese University Press, pp. 337-58.
Stevenson, H. (2010) New Organisations? Alternative Leadership. Assessing the Role of Union Learning Representatives as Leaders of Professional Learning. Paper presented at the BELMAS Annual Conference, Wokefield Park, Reading, 911 July.

Syed, K. T. (2008) 'A Chinese teacher's perspective on professional development in literacy education'. International Electronic Journal for Leadership in Learning, 12(10). Online at: http://www.ucalgary.ca/iejll/vol12/syed (accessed January 2010).

Timperley, H. (2008) Teacher Professional Learning and Development, Educational Practices Series, 18th edn. Brussels: International Academy of Education.

Topping, K. (1988) The Peer Tutoring Handbook. London: Croom Helm.

Webb, R. (2007) Primary Schools as Professional Learning Communities: Rhetoric and Reality. Paper presented at the BERA Annual Conference, Institute of Education, University of London, 5-8 September. 